\title{
Numerical Prediction of Wall Pressure Fluctuations in a Turbulent Boundary Layer on a Cylinder in Axial Flow
}

\author{
E. Arunachalam, K. Karthik, S. Jeyakumar
}

\begin{abstract}
Flow noise originating in the turbulent boundary layer (TBL) often severely limits the performance of towed sonar cylinder and therefore it is necessary to predict this noise for the design of efficient towed cylinder. This paper presents large eddy simulation methodology to establish the TBL properties and wall pressure fluctuations on a $3 \mathrm{~m}$ long cylinder with length to diameter ratio of 315 in the operating speed of $11.4 \mathrm{~m} / \mathrm{s}$ in air. The computed flow induced sound is compared with experimental measurement available in the literature successfully. The effectiveness of scaling the flow noise spectra with diameter and tow speed is discussed and non-dimensional wall pressure spectra presented with respect to non-dimensional frequency. The overall sound pressure levels are also compared with experimental data that show good accuracy achieved by the proposed numerical methodology.
\end{abstract}

Keywords : Axial flow; Flow induced sound; LES; CFD

\section{INTRODUCTION}

Thin and long towed sonar cylinders are used by small autonomous underwater platforms for underwater surveillance, aquatic mammal studies and seismic prospecting. The turbulent boundary layer (TBL) wall pressure fluctuations on the cylinder surface is the primary source of flow noise that affects the detection efficiency(Cipolla and Keith, 2008; Foley et al., 2011). The development of digital, thin and long cylinders for the autonomous underwater vehicles requires a methodology to predict the TBL induced flow noise levels.

The wall pressure fluctuation in TBL has been studied for a long time), where principal motivation was the spatial resolution of pressure field measured by finite size transducers(Corcos, 1967, 1963; Skudrzyk and Haddle, 1960). The noise due to wall pressure fluctuations has been called 'pseudo-sound' in the literature(Smol'yakov, 2000). Much experimental work has been done on TBL noise for flow over flat plate wherein the power spectral density (PSD) of wall pressure fluctuations were reported in addition to accurate measurement of boundary layer parameters under

Revised Manuscript Received on December 5, 2019

* Correspondence Author

E Arunachalam, Ramesh Babu S, Department of Mechanical Engineering, Kalasalingam Academy of Research and Education, Krishnankoil, Srivilliputhur, Tamil Nadu 626128

Karthik K *, Department of Aeronautical Engineering, Kalasalingam Academy of Research and Education, Krishnankoil, Srivilliputhur, Tamil Nadu 626128. Karthik@klu.ac.in

Jeyakumar S, Department of Aeronautical Engineering, Kalasalingam Academy of Research and Education, Krishnankoil, Srivilliputhur, Tamil Nadu 626128 zero, favourable and adverse pressure gradients(Schloemer, 1967). A large variety of semi- empirical formulae for PSD had also been proposed over the years(Hwang et al., 2009).

In comparison to flow over a flat plate, thecorresponding problem of TBL pressure fluctuations in cylinders in axial flow, a problem of considerable interest in underwater towed cylinder sonar, has received only limited attention. Early experimental studies of the TBL over a cylinder in axial flow were carried out for the radius based Reynolds number Rea (= $\rho \mathrm{Ua} / \mu \mathrm{D}, \mathrm{U}$ is the axial flow speed, is the cylinder radius, $\rho$ is the ranged from 425 to 134,000 (Willmarth and Yang, 1970). Although the study of TBL properties along towed cylinder had been investigated density of water and $\mu$ is the viscosity of fluid) collectively. Extensively for the past several decades, only a limited attention had been given to the determination of flow noise levels (i.e. wall pressure fluctuations) on such cylinders. From the previous experimental observations, the TBL of a thin cylinder is relatively thick $(\delta / \mathrm{a}>>1$, where $\delta$ is the boundary layer thickness and a is the cylinder radius) and fall in the high Reynolds number (Re) category(Keith et al., 2008). The experimental measurements on the surface shear stress distributions in the range of $300<$ Rea 50000 are validated with the numerical simulations(Tutty, 2008), and found that the dominant turbulent activity was positioned in the near-wall zone when compared to the outer flow.

Only a few large eddy simulation (LES) based investigations had been reported that attempted to obtain TBL properties such as skin friction coefficient (Cf), transverse curvature $(\delta / \mathrm{a})$ and shape factor $\left(\delta^{*} / \theta\right.$, where $\delta^{*}$ is the displacement thickness and $\theta$ is the momentum thickness of the TBL) for a thin long cylinder(Jordan, 2014a, 2014b, 2011; Tutty, 2008). Tutty (2008) performed LES on axial flow past circular cylinders of various diameters covering a wide range of Rea(6203 to 92310). For this category of flows, Tutty (2008) presented the TBL properties and compared some of his results with the measurements (Willmarth et al., 1976). Also, he discussed the wall pressure fluctuations and reported the spectra, but without any experimental verification. Jordan $(2011,2014 a, 2014 b)$ took the LES route to the TBL over cylinders, and suggested semi-empirical formulae for skin friction coefficient that works over a large range of Rea, but did not visit the problem of TBL wall pressure spectrum. 
Based on the above discussion, it can be said that there is no paper that reports numerically computed TBL wall pressure spectrum, a measure of flow noise in TBL, with experimental validation. The present paper attempts this. It takes the LES route to determine the TBL length scales as well as the pressure fluctuations on the surface of a towed cylinder (i.e. flow noise levels) and their spectral content. We address this problem by assembling the relevant numerical evidence from the past literature that covers a suitable range of Rea for our application.

\section{PROBLEM DEFINITION}

The long and thin cylinder considered in this work has a length (L) of $3 \mathrm{~m}$ and diameter (D) of $10 \mathrm{~cm}$, at speed

(U) $11.4 \mathrm{~m} / \mathrm{s}$. The experiments were carried out in low speed low noise wind tunnel. It was constructed with a vertical orientation to eliminate boundary layer symmetry problems associated with cylinder sag. The pressure fluctuations due to flow noise on the cylinder surfaceweremeasured at apoint $2.48 \mathrm{~m}$ from the leading end of the cylinder and processed. In the present work, the cylinder is considered rigid, and the fluid flow is axial. In order to validate the LES results, TBL properties are compared with the experimental findings(Snarski and Lueptow, 2006).

\section{COMPUTATIONAL METHODOLOGY}

The dimensions of the computational domain for the LES are shown in Fig. 1. The axis system and the pressure monitoring location $(\mathrm{x}=2.48 \mathrm{~m})$ are also shown in this figure.
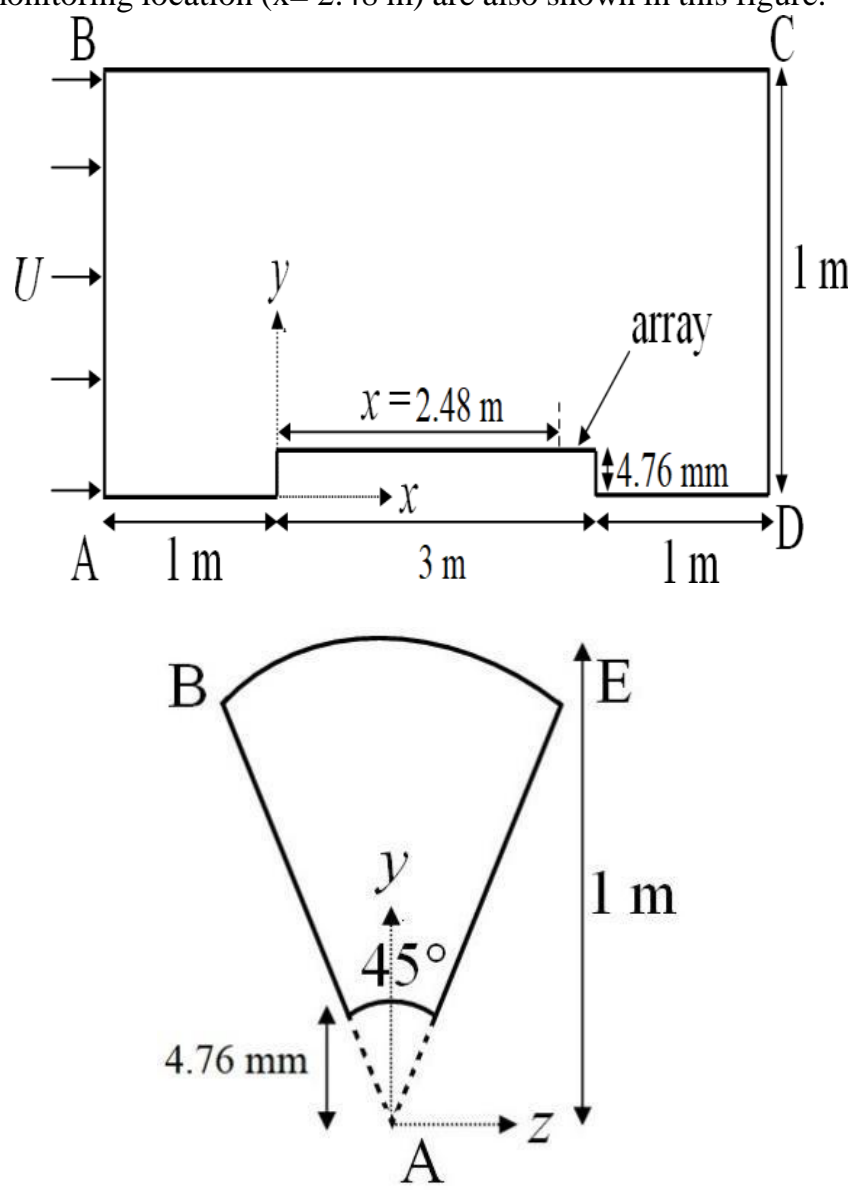

Figure 1: Dimensions of the computational domain. (a) Front view (b) side view. (Not to scale)
The high $\mathrm{L} / \mathrm{D}(=630)$ ratio of the cylinder and the fine mesh requirements around the cylinder (i.e. spatial resolution) dictated by LES make the computation model very large. To capture the realistic three-dimensional flow features that LES yields, and yet to economize on the mesh size, we have adopted an approach wherein a $45^{\circ}$ segment of the axisymmetric domain is retained in the calculations (Fig. 1b) by utilizing the rotational periodicity condition. Several segment angles were tried, e.g. $5^{\circ}$ and $15^{\circ}$, but these yielded poor results in the sense that the pressure fluctuations on the cylinder surface were not captured well. The $45^{\circ}$ and larger segment angles captured the pressure fluctuations well and therefore a $45^{\circ}$ segment is adopted in all calculations.

The boundary conditions are straightforward, namely, velocity inlet over the face $A B$ where constant free stream velocity (U) is prescribed, pressure outlet over the face $\mathrm{CD}$ (maintained at constant static gauge pressure which is set to zero), zero shear stress condition on the cylindrical boundary $\mathrm{BC}$ and no-slip condition over the cylinder surface. On the segment end faces, $\mathrm{AB}$ and $\mathrm{AE}$, rotational periodicity condition was applied.There are 3000 cells in the axial direction, 40 cells in the circumferential direction over the $45^{\circ}$ segment. This gives an acceptable spatial resolution for capturing the TBL, especially the cross flow vertical motion in the inner and outer layers of the TBL(Jordan, 2011). The number of cells in the radial direction is 28 , with the first cell distance from thecylinder surface as $10-5 \mathrm{~m}$ with a growth ratio of 1.2.The spatialresolution $\mathrm{x}+$ in this paper is maintained to be 70 which conforms to the LES requirements reported by Tutty (2008) (i.e. $x+\leq 85.5)$. To fully resolve the laminar sub layer of the TBL, a near wall resolution of $\mathrm{y}+=$ 0.9 has been maintained in this work (Tutty, 2008). The grid system contains a total number of 3.7 million cells.

A grid independence study was conducted prior to launching the final simulations. The objective was to obtain the near optimal grid sizing so that the overall computational resource requirement is manageable. Thus, four levels of local refinement have been used with the number of cells ranging from 2.57 million to 4.44 million cells. The parameter chosen for grid independence test is the time- averaged skin friction coefficient (Cf) for $U=11.4 \mathrm{~m} / \mathrm{s}$. The results for various grids are presented in Table 1 for $\mathrm{Cf}$, which shows a variation of $23.53 \%$ and $0 \%$ between the coarsest ( 2.57 million cells) and the finest grids (4.4 million cells) and between the intermediate (3.7 million cells) and the finest grids respectively. So, all the computations have been carried out using a mesh of 3.7 million cells.

Table 1: Grid independence test for speed of $11.4 \mathrm{~m} / \mathrm{s}$.

\begin{tabular}{|c|c|c|}
\hline $\begin{array}{c}\text { Refinement } \\
\text { level }\end{array}$ & $\begin{array}{c}\text { No. of cells } \\
\text { (Millions) }\end{array}$ & $C_{f}$ \\
\hline 1 & 2.57 & 0.0040 \\
\hline 2 & 3.08 & 0.0042 \\
\hline 3 & 3.70 & 0.0045 \\
\hline 4 & 4.44 & 0.0045 \\
\hline
\end{tabular}

The finite volume method with the second-order upwind scheme, which guarantees second order precision, is used for the spatial discretization. 
The SIMPLE algorithm is used for pressure-velocity coupling. First order implicit unsteady formulation is utilized which is unconditionally stable with respect to the size of the time step. A variable (i.e. adaptive) time stepping method where the time steps are adjusted automatically with respect to the truncation error is used. The time step is allowed to change in between 10-3 s and 10-7 s. When the residuals of all variables fall below 10-5, the solution has been regarded as converged. In this paper, LES computations are performed with a Smagorinsky constant of0.1(Breuer, 1998).

\section{RESULTS AND DISCUSSION}

The present work is concerned with achieving a consistent LES model that yields reasonably accurate TBL characteristics and flow noise levels of thin and long cylinders. The accuracy of the computed flow noise levels using LES mainly depends on the TBL properties, which is the major challenge for thin and long cylinder application. The unsteady averaging of the flow properties is carried out when the turbulent flow has reached a statistically steady about $10.08 \%$ below the value 1.27 obtained from the momentum-integral analysis for Prandtl's 1/7th velocity profile for flow over a flat plate(Houghton et al., 2016).

Experimental analysis of flow noise levels for the cylinder was reported in Snarski and Lueptow (2006), as described in Section 2. The pressure fluctuations were measured at a point on the cylinder surface located at $\mathrm{x}=2.48 \mathrm{~m}$ (see Fig. 1) when the cylinder has attained a steadyspeed.To obtain spectral information from LES, the time series of the wall pressure are transformed into the Fourier space using Hann window based on the Welch method (Welch, 1967)with 50\% overlap and 12 data segments(Oppenheim and Schafer, 2009). The acoustic spectrum provides a measure of the total sound energy as a function of frequency from all acoustic sources. A Mat lab code is used toestimate the power spectral density of wall pressure $(\cdot p)$ and the sound pressure level is computed as. In all calculations, the total simulationtime is $13.2 \mathrm{~s}$ and the last $1 \mathrm{~s}$ of time history data are used for computing the TBL properties. The TBL properties such as skin friction coefficient $(\mathrm{Cf})$,transverse curvature $(\delta / \mathrm{a})$ and shape factor $(\delta * / \theta)$ are compared with previous works.

The shape factor $\delta * / \theta$ is computed from theLES solutions using the following relations (White, 1969): computed spectra compare quite well with the experimental spectra. It can be seen that the TBL wall pressure fluctuations are predominant in the lower frequency regime which is approximately $0-500 \mathrm{~Hz}$. At frequencies higher than roughly $500 \mathrm{~Hz}$, the results show a significant decrease in energy. Comparisons between $\mathrm{Cf}, \delta / \mathrm{a}$ and $\delta * / \theta$ estimated using LES and that obtained from the experimental measurements showing reasonably good agreement.

Table 2: Comparison of TBL properties: present LES vs. experiments.

\begin{tabular}{|c|c|c|}
\hline \multirow{2}{*}{$\begin{array}{c}\text { TBL } \\
\text { properties }\end{array}$} & \multicolumn{2}{|c|}{$\begin{array}{l}U=11.4 \mathrm{~m} / \mathrm{s} \\
\left(R e_{a}=5134\right)\end{array}$} \\
\cline { 2 - 3 } & Exp. & LES \\
\hline
\end{tabular}

\begin{tabular}{|l|l|l|}
\hline$C_{f}$ & 0.0047 & 0.0045 \\
\hline$\delta / a$ & 5.04 & 5.11 \\
\hline$\delta / \theta$ & 1.136 & 1.142 \\
\hline
\end{tabular}

The parameters $\delta / \mathrm{a}$ and $\delta^{*} / \theta$ are computed from using LES data and compared with values obtained from semi-empirical relations in Table 2 showing reasonably good agreement. It is seen that the shape parameter $\delta^{* / \theta}$ of the cylinder is nearly 1.1142 .

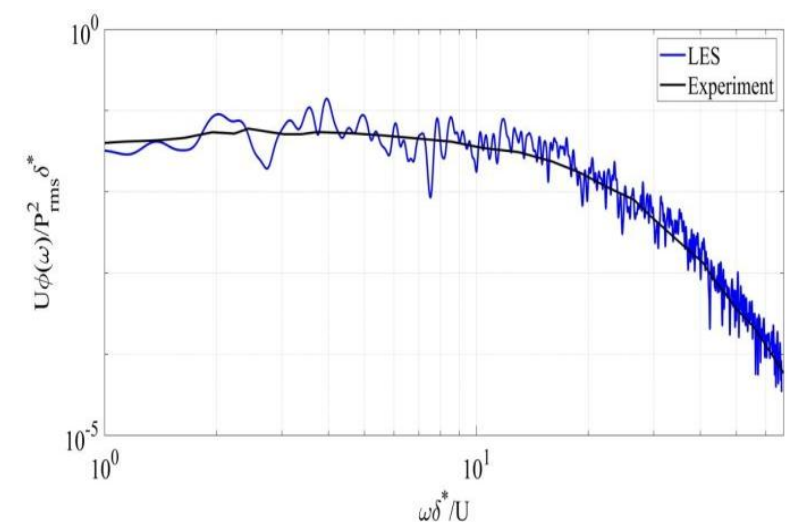

Figure 2: Comparison of numerical flow noise spectrum with experiment estimates at speed of $11.4 \mathrm{~m} / \mathrm{s}$.

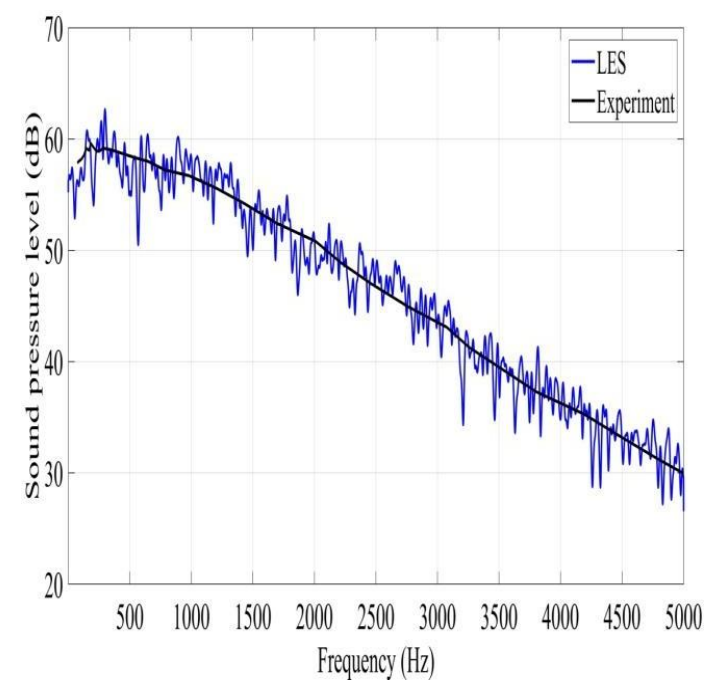

Figure 3: Non-dimensional flow noise spectra

\section{CONCLUSION}

The TBL properties and the corresponding flow noise levels due to a thin and long cylinder towed in a speed of $11.4 \mathrm{~m} / \mathrm{sis}$ numerically computed using LES. The parameters $\mathrm{Cf}, \delta / \mathrm{a}$, $\delta^{*} / \theta$ and SPL (f) obtained from LES are compared with the experimental data from the literature with success. The shape factor $\left(\delta^{*} / \theta\right)$ for the TBL of the thin- long cylinder is 1.1142 , which is about $10.08 \%$ below the value of 1.27 that results from the momentum-integral analysis for Prandtl's1/7th velocity profile valid for a flat plate. The flow noise levels are dominant at low frequency region and reduce its value at higher frequencies. \& Sciences Publication 
The oceanographic community is expected to benefit from this study by estimating the TBL properties and the flow noise levels with reasonably good accuracy in the design of thin and long sonar cylinder. Future work will be aimed at estimating the impact of surface roughness of the cylinder that may reduce the flow noise levels.

\section{REFERENCES}

1. Breuer, M., 1998. Numerical and modeling influences on large eddy simulations for the flow past a circular cylinder. Int. J. Heat Fluid Flow. https://doi.org/10.1016/S0142-727X(98)10015-2

2. Cipolla, K.M., Keith, W.L., 2008. Measurements of the wall pressure spectra on a full-scale experimental towed array. Ocean Eng. 35, 10521059. https://doi.org/10.1016/j.oceaneng.2008.02.006

3. Corcos, G.M., 1967. The resolution of turbulent pressures at the wall of a boundary layer. J. Sound Vib. 6, 59-70. https://doi.org/10.1016/0022-460X(67)90158-7

4. Corcos, G.M., 1963. Resolution of Pressure in Turbulence. J. Acoust. Soc. Am. https://doi.org/10.1121/1.1918431

5. Foley, A.W., Keith, W.L., Cipolla, K.M., 2011. Comparison of theoretical and experimental wall pressure wavenumberfrequency spectra for axisymmetric and flat-plate turbulent boundary layers. Ocean Eng. 38,1123-1129. https://doi.org/10.1016/j.oceaneng.2011.05.001

6. Houghton, E.L., Carpenter, P.W., Collicott, S.H., Valentine, D.T., 2016. Aerodynamics for Engineering Students: Seventh Edition, Aerodynamics for Engineering Students: Seventh Edition.

7. Hwang, Y.F., Bonness, W.K., Hambric, S.A., 2009. Comparison of semi-empirical models for turbulent boundary layer wall pressure spectra. J.

Sound Vib. https://doi.org/10.1016/j.jsv.2008.06.002

8. Jordan, S.A., 2014a. On the Axisymmetric Turbulent Boundary Layer Growth Along Long Thin Circular Cylinders. J. Fluids Eng. https://doi.org/10.1115/1.4026419

9. Jordan, S.A., 2014b. A simple model of axisymmetric turbulent boundary layers along long thin circular cylinders. Phys. Fluids. https://doi.org/10.1063/1.4893541

10. Jordan, S.A., 2011. Near-wall turbulent characteristics along very long thin circular cylinders. J. Fluids

Struct. https://doi.org/10.1016/j.jfluidstructs.2010.11.008

11. Keith, W.L., Cipolla, K.M., Furey, D., 2008. Turbulent wall pressure fluctuation measurements on a towed model at high Reynolds numbers.

Exp. Fluids. https://doi.org/10.1007/s00348-008-0552-y

12. Oppenheim, A. V, Schafer, R.W., 2009. Discrete Time Signal Processing. Book.

13. Schloemer, H.H., 1967. Effects of Pressure Gradients on Turbulent-Boundary-Layer Wall-Pressure Fluctuations. J. Acoust. Soc. Am. 42, 93-113. https://doi.org/10.1121/1.1910581

14. Skudrzyk, E.J., Haddle, G.P., 1960. Noise Production in a Turbulen Boundary Layer by Smooth and Rough Surfaces. J. Acoust. Soc. Am. https://doi.org/10.1121/1.1907871

15. Smol'yakov, A. V., 2000. Calculation of the spectra of pseudosound wall-pressure fluctuations in turbulent boundary layers. Acoust. Phys. https://doi.org/10.1134/1.29890

16. Snarski, S.R., Lueptow, R.M., 2006. Wall pressure and coherent structures in a turbulent boundary layer on a cylinder in axial flow. J. Fluid Mech. 286, 137. https://doi.org/10.1017/s0022112095000681

17. Tutty, O.R., 2008. Flow along a long thin cylinder. J. Fluid Mech. 602 1-37. https://doi.org/10.1017/S0022112008000542

18. Welch, P.D., 1967. The Use of Fast Fourier Transform for the Estimation of Power Spectra: A Method Based on Time Averaging Over Short, Modified Periodograms. IEEE Trans. Audio Electroacoust. https://doi.org/10.1109/TAU.1967.1161901

19. White, F.M., 1969. The Axisymmtric Turbulent Boundary Layer On an Extremley Long Cylinder, NUSL Report.

20. Willmarth, W.W., Winkel, R.E., Sharma, L.K., Bogar, T.J., 1976. Axially symmetric turbulent boundary layers on cylinders: Mean velocity profiles and wall pressure fluctuations. J. Fluid Mech. https://doi.org/10.1017/S002211207600311X

21. Willmarth, W.W., Yang, C.S., 1970. Wall-pressure fluctuations beneath turbulent boundary layers on a flat plate and a cylinder. $\mathrm{J}$. Fluid Mech. https://doi.org/10.1017/S0022112070000526

\section{AUTHORS PROFILE}

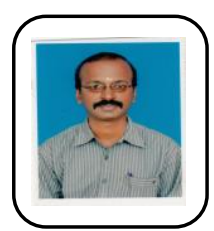

Dr. S. Jeyakumar working as Professor in Aeronautical Engineering, Kalasalingam Academy of Research and Education. The author has published papers in the areas of high-speed flow mixing and combustion, cavity flow, dual combustion ramjet engine.

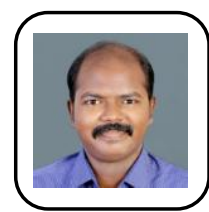

K. Karthik working as Assistant Professor in Aeronautical Engineering, Kalasalingam Academy of Research and Education. The author has published papers in the areas of CFD, and aero acoustics.

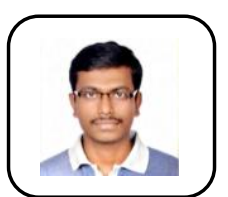

E. Arunachalam was a student of Kalasalingam Academy of Research and Education and is currently working as production engineer in Chennai, India 